\title{
Trends in fatalities due to poisoning at Umtata General Hospital, Мтhatha (1993-2005)
}

Author:

Banwari L. Meel ${ }^{1}$

\section{Affiliation:}

${ }^{1}$ Department of Forensic

Medicine, Walter Sisulu

University, South Africa

Correspondence to:

Banwari L. Meel

e-mail:

bmeel@wsu.ac.za

Postal address:

Private bag X1 UNITRA,

Mthatha, 5100, South

Africa

\section{Keywords:}

poisoning; traditional

medicine; mortality;

suicide; autopsy

\section{Dates:}

Received: 12 Mar. 2009

Accepted: 22 June 2009

Published: 18 Aug. 2009

How to cite this article: Meel BL. Trends in fatalities due to poisoning at Umtata General Hospital, Mthatha (19932005). Afr J Prm Health Care Fam Med. 2009;1(1), Art. \#49, 3 pages. DOI: 10.4102/phcfm.v1i1.49

\section{Note:}

A part of this article has been previously published as a Letter to the Editor in Vol 49, No 7 of the South African Family Practice Journal.

(C) 2009. The Authors. Licensee: OpenJournals Publishing. This work is licensed under the Creative Commons Attribution License.

\section{ABSTRACT}

Poisoning is a common method of committing suicide in this region of South Africa. Females generally ingest poisons but it is increasingly becoming common in males too. This is a record review of autopsies carried out at the Umtata (Mthatha) General Hospital mortuary, which forms part of the teaching hospital of the Walter Sisulu University Medical School. There were 10230 unnatural deaths between 1993 and 2005. Of these deaths, 161 (1.6\%) were deaths due to poisoning. There was a marked increase in death by poisoning from $2.5 \%$ in 1993 to $13.7 \%$ in 2004 . The highest percentage (17.4\%) of poison-related deaths was in 2001, and the lowest (2.5\%) was in 1993 and 1994 . About two-thirds of victims $(66 \%)$ were males, and more than half of the victims $(51.5 \%)$ were in the 11 to 30 age group. There is an increasing trend in fatalities due to poisoning at Umtata General Hospital, Mthatha.

\section{INTRODUCTION}

The global incidence of poisonings is not known. It is speculated that up to half a million people die each year as a result of various kinds of poisoning, including poisoning by natural toxins. The incidence of pesticide poisoning, which is high in developing countries, has doubled during the past 10 years. ${ }^{1}$ Poisoning continues to be an important public health problem in the United States. In 1995, two million incidences of human poison exposures were reported to all poison centres in the United States. ${ }^{2}$

Data on mortality in Africa is inadequate. The death rate in South Africa is 9.4 per 1000, so approximately 400000 persons out of a population of 40 million die each year. ${ }^{3}$ About $20 \%$ of all deaths are due to unnatural causes, excluding violence, accidents and self-inflicted death. ${ }^{3} 20 \%$ of 400000 clearly suggests that 80000 deaths per annum occur from unknown causes, of which a large proportion could possibly be attributed to traditional African medicine. ${ }^{4}$

The leading cause of death from acute poisoning in South Africa is from traditional medicines such as muti, which cause $51.7 \%$ of poison-related mortality. Sangomas (traditional healers) provide basic health care to an estimated $80 \%$ of South Africa's 40 million people, most of whom cannot afford western-style health care. ${ }^{5}$ Deaths related to poisoning appear to be increasing in the Mthatha area. The purpose of this study is to highlight the problem of poisoning-related deaths and its relation to the demographics of the area.

\section{METHOD}

This is a record review of autopsies done at the Umtata (Mthatha) General Hospital mortuary between January 1993 and December 2005. This mortuary serves a population of approximately 400000 people, and is attached to the Walter Sisulu University Medical School . All autopsies were recorded in the postmortem register. Records included names, addresses and ages of the deceased, together with causes of death. All cases of poisoning are based on the history as recorded by the police and as related by the next of kin. Results were collated and analysed manually, and presented in graphic form with the help of a computer program.

\section{RESULTS}

There were 10230 unnatural deaths between 1993 and 2004. Of these deaths, 161 (1.6\%) were deaths due to poisoning (Figure 1). There was an increase from $2.5 \%$ in 1993 to $13.7 \%$ in 2005 . This increase in trend has been observed in both genders. Among males, it has increased from $1.9 \%$ in 1993 to $9.4 \%$ in 2005, while among females it increased from $0.6 \%$ to $4.3 \%$ over the same period (Table 1 and Figure 2). The highest frequency (17.4\%) of poisoning fatalities occurred in 2001, and the lowest in 1993 and 1994 (Table 1 and Figure 2). About two-thirds (66\%) were males with a ratio of males to females of 2.15:1 (Table 2 and Figure 3). More than half (51.5\%) were in the 11 to 30 year age group, and only $4.9 \%$ were between the ages of 51 and 60 years. (Table 2 and Figure 4).

\section{DISCUSSION}

This record review is the only inquiry into poison fatalities in this region of South Africa. It provides an important insight which can serve as justification for a comprehensive study of the subject. Poisoningrelated deaths in Africa are grossly under-investigated, and therefore under-estimated. Hardly any studies have been carried out in this area, despite the fact that a significant number of poison-related autopsies have been conducted. The poisoning pattern reported at Ga-Rankuwa hospital in Gauteng is very similar to that reported in Bloemfontein (and Zimbabwe). Traditional African Medicine, the major cause of mortality, is responsible for $51.7 \%-62 \%$ of deaths. ${ }^{6}$ Almost $85 \%$ of people living in rural areas will consult a traditional healer before going to a medical doctor, clinic or hospital when they are sick. ${ }^{7}$ In many cases where people die without reaching a hospital, relatives do not often admit to ingestion of a traditional remedy. ${ }^{7}$ It is not possible to determine the true cause of death in all cases because symptoms and signs of poisoning by herbs closely mirror the major causes of death among the South African black population. ${ }^{4}$ 
TABLE 1

Trends in fatalities due to poisoning (1993-2005) at Umtata General Hospital, Mthatha, South Africa

\begin{tabular}{|c|c|c|c|c|}
\hline YEARS & MALE (\%) & FEMALE (\%) & & TAL (\%) \\
\hline 1993 & $3 \quad(1.9 \%)$ & $1 \quad(0.6 \%)$ & 4 & $(2.5 \%)$ \\
\hline 1994 & $1 \quad(0.6 \%)$ & $3 \quad(1.9 \%)$ & 4 & $(2.5 \%)$ \\
\hline 1995 & $2 \quad(1.2 \%)$ & $4 \quad(2.5 \%)$ & 6 & $(3.7 \%)$ \\
\hline 1996 & $2 \quad(1.2 \%)$ & $3 \quad(1.9 \%)$ & 5 & $(3.1 \%)$ \\
\hline 1997 & $6 \quad(3.7 \%)$ & $1 \quad(0.6 \%)$ & 7 & $(4.3 \%)$ \\
\hline 1998 & $11 \quad(6.8 \%)$ & $3 \quad(1.9 \%)$ & 14 & $(8.7 \%)$ \\
\hline 1999 & $9 \quad(5.6 \%)$ & 2 (1.2\%) & 11 & $(6.8 \%)$ \\
\hline 2000 & $10 \quad(6.2 \%)$ & $6 \quad(3.7 \%)$ & 16 & $(9.9 \%)$ \\
\hline 2001 & $18 \quad(11.2 \%)$ & $10(6.2 \%)$ & 28 & (17.4\%) \\
\hline 2002 & 12 (7.5\%) & $3 \quad(1.9 \%)$ & 15 & $(9.4 \%)$ \\
\hline 2003 & $7 \quad(4.3 \%)$ & $5 \quad(3.1 \%)$ & 12 & $(7.4 \%)$ \\
\hline 2004 & $14(8.7 \%)$ & $3 \quad(1.9 \%)$ & 17 & (10.6\%) \\
\hline 2005 & $15(9.4 \%)$ & $7 \quad(4.3 \%)$ & 22 & (13.7\%) \\
\hline TOTAL & $110(66 \%)$ & $51(34 \%)$ & 161 & $(100 \%)$ \\
\hline
\end{tabular}
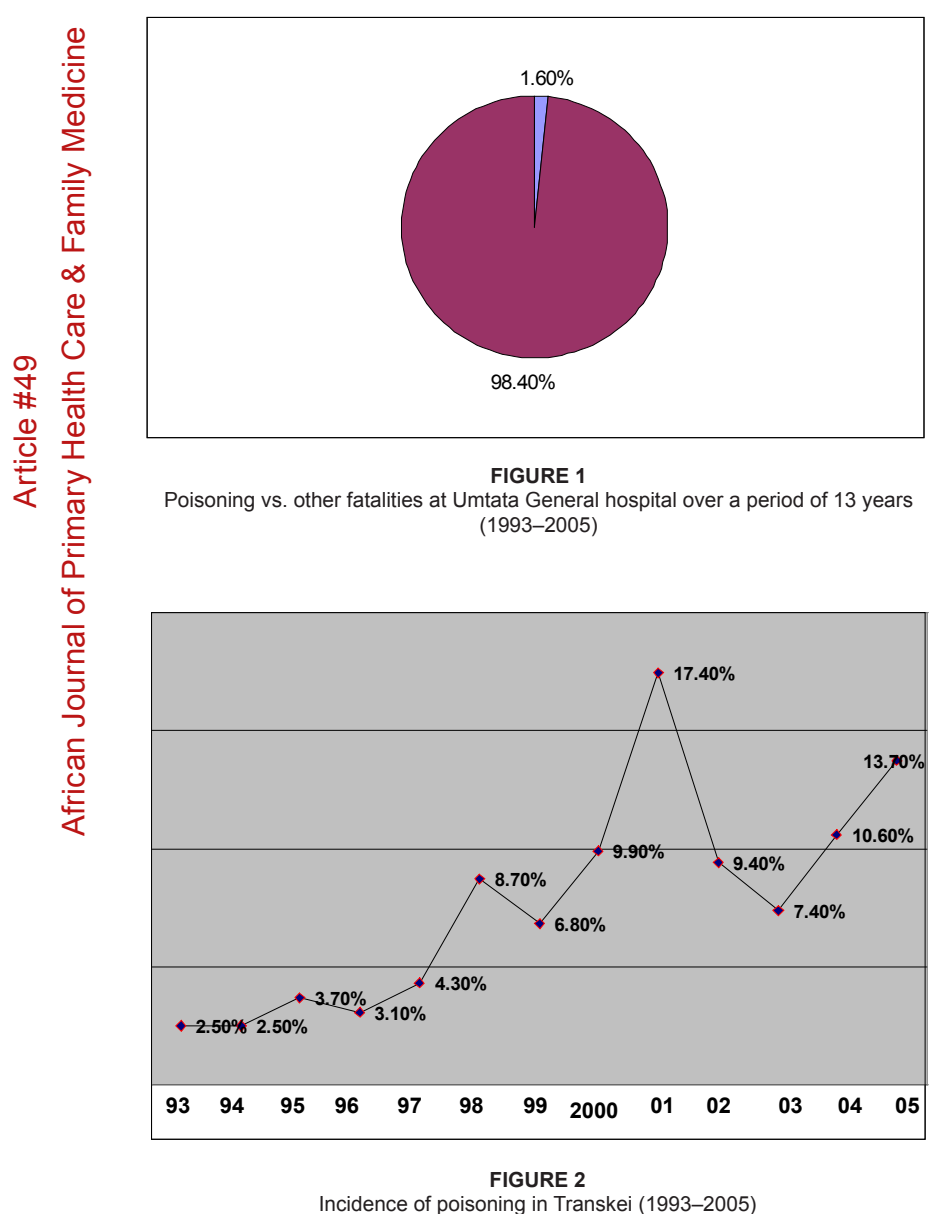

The mortality rate in developed countries is low in comparison to the developing world and intentional poisonings in the former are rare. There were 10230 unnatural deaths between 1993 and 2005 in the Mthatha area. Of those deaths, $161(1.6 \%)$ were deaths due to poisoning (Figure 1). The National Injury Mortality Surveillance System (NIMSS) report showed that poisoning is not among the top 10 external causes of death in South Africa. ${ }^{8}$ In the Mthatha area it is, however, the eighth most common cause of unnatural death. The major cause of mortality was traditional medicines (51.7\%). ${ }^{6}$ The local Xhosa people who inhabit this area believe in traditional medicines to cure their
TABLE 2

Male versus female deaths due to poisoning (1993-2005) at Umtata General Hospital

\begin{tabular}{|c|c|c|c|}
\hline YEARS & MALE (\%) & FEMALE (\%) & TOTAL (\%) \\
\hline 1 to 10 & $(2.5 \%)$ & 2 (1.2\%) & $\begin{array}{ll}6 & (3.7 \%)\end{array}$ \\
\hline 11 to 20 & $19 \quad(11.8 \%)$ & $21(13 \%)$ & $40 \quad(24.8 \%)$ \\
\hline 21 to 30 & $32 \quad(19.9 \%)$ & $11(6.8 \%)$ & $43 \quad(26.7 \%)$ \\
\hline 31 to 40 & $22 \quad(13.7 \%)$ & $9 \quad(5.6 \%)$ & 31 (19.3\%) \\
\hline 41 to 50 & $17 \quad(10.6 \%)$ & $4 \quad(2.5 \%)$ & 21 (13.1\%) \\
\hline 51 to 60 & $(4.3 \%)$ & $1 \quad(0.6 \%)$ & $(4.9 \%)$ \\
\hline 61 and above & $9 \quad(5.6 \%)$ & $3 \quad(1.9 \%)$ & $12(7.5 \%)$ \\
\hline TOTAL & $110(68.4 \%)$ & $51(31.6 \%)$ & $161(100 \%)$ \\
\hline
\end{tabular}

illnesses. These medicines are mainly herbal preparations. They are prescribed by sangomas or izinyangas - traditional healers from African indigenous groups. ${ }^{9}$ Alcohol-related mortality is also very high in this area. Approximately $25 \%$ of all hospital admissions in South Africa are directly or indirectly related to alcohol use. ${ }^{10}$

There is little information on the effect of HIV / AIDS on people taking poisons to take their own lives. Poisoning-related deaths, however, have increased from $2.5 \%$ in 1993 to $13.7 \%$ in 2005 (Table 1 and Figure 2). This is more than a five-fold increase over a period of 13 years. During the same period, the increase in the established prevalence of HIV infection in South Africa also rose from $14.2 \%$ (1996) to $24.5 \%$ (2000). ${ }^{11}$

More males died as a result of poisoning (68.4\%) than women (table 2 and figure 3). A similar observation was also reported in Ga-Rankuwa hospital in South Africa where $60 \%$ of fatalities were males. ${ }^{12}$ The major problem area is poisoning by traditional medicines, which are mainly of plant origin. It is difficult to make a firm diagnosis in these cases. The histories are vague and patients rarely disclose the source of the substances responsible. Fatalities with traditional medicine are as high as $87 \%{ }^{13}$ Traditional healers (herbalists) cannot be held responsible for selling these toxic herbs as new laws that have been passed recognise them. There are an estimated 200000 indigenous traditional healers in South Africa. Witchcraft is yet another force to be reckoned with in many black Southern African indigenous cultures. Undoubtedly there are some individuals who wilfully perform antisocial acts with the intention to harm people (like in any other culture) and thus can be considered guilty of witchcraft. The use of human body parts as muti (traditional medicine) by some traditional healers in South Africa is an example of the perverse nature of the muti industry. ${ }^{14}$ This particular study did not have as part of its brief the types of poisons used by people, but according to the histories, a large number had ingested herbs, organophosphates or carbon disulphide.

Most deaths (26.7\%) occurred in the 21 to 30 year age group (Table 2 and Figure 4). A study carried out in Zimbabwe (1992) showed that the majority of patients admitted to hospitals following incidences of poisoning were between 21 and 30 years, and poisoning by traditional medicines was the main cause of these admissions. ${ }^{15}$ In this study, the pattern of poisoning between the deceased differed and can be attributed to varying cultural beliefs. When committing suicide, males used more violent methods such as hanging, shooting and jumping from heights whereas females used substance overdoses. ${ }^{16}$ Attempted suicide by substance abuseis more common in females but completed suicide by the same method is more prevalent among males. According to this study, fatalities are twice as high among males as females. The ever increasing HIV infection and poor support system for persons diagnosed with this disease could be responsible for several deaths, particularly in the younger age groups. It is essential to develop a better understanding of traditional medicine and to make provision for the establishment of a poison control centre. Clinical toxicology is still not 


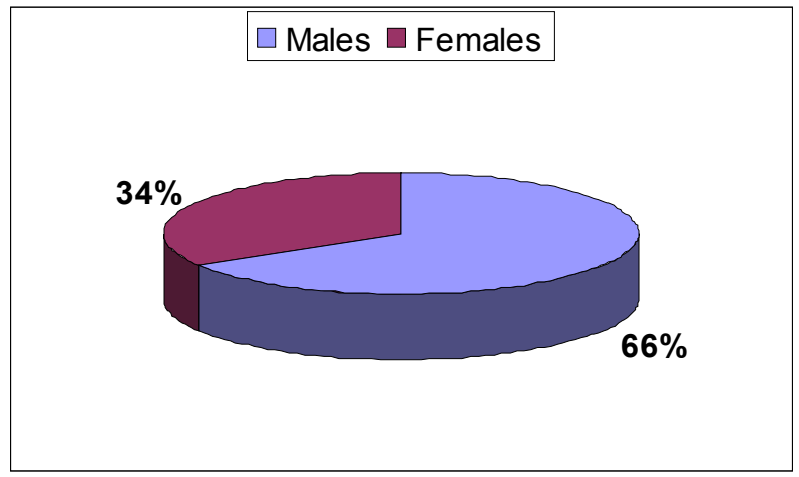

FIGURE 3

Male vs. female poisoning in Transkei (1993-2005)

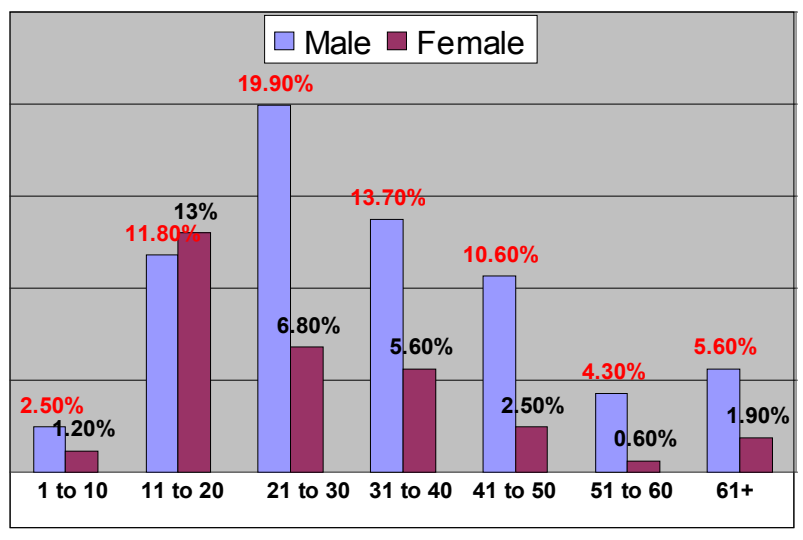

FIGURE 4

Male vs. female fatal poisoning in different age groups (1993-2005)

acknowledged as a separate medical discipline in most countries, including South Africa. Primary health care physicians should be trained in this emerging specialty.

\section{Conclusion}

There is an increasing trend in fatalities due to poisoning at Umtata General Hospital, Mthatha.

\section{REFERENCES}

1. UN, ILO \& WHO. Guidelines for poison control [homepage on the Internet]. 1997 [cited 2006 Jul 28]. Available from: http://www.intox.org/databank/documents/supplem/ sup3.htm.
2. McCaig LF, Burt CW. Poisoning-related visits to emergency departments in United States, 1993-1996. J Toxicol Clin Toxicol. 1999;37(7):817-826.

3. South African Department of Health. Annual statistics on unnatural deaths in South Africa. Pretoria: Government Printers; 2004.

4. Popat A, Shear NH, Malkiewicz I, et al. Traditional African Medicine Toxicity "Impila". Clin Biochem. 2001;34(3):223229.

5. Griffin M, Keshish S, Perrella E. Five minutes to midnightMuti Medicine [homepage on the Internet]. 2004 [cited 2006 Jul 30]. Available from: http://i2r.org/fmm/issues/ december2004/article3.html.

6. Joubert P. The major causes of mortality by traditional African Medicine. J Clin Toxicol. 1990;28(1):5-9.

7. Whinnery E. Traditional healers in South Africa. American Council for Voluntary International Action [homepage on the Internet]. 2003 [cited 2008 Sep 28]. Available from: http://www.interaction.org/library/detail.php?id=2258 .

8. National Injury Mortality Surveillance System (NIMSS). A profile of fatal injuries in South Africa. Fourth annual report of the National Injury Mortality Surveillance System [homepage on the Internet]. 2002 [cited n.d.]. Available from: http://www.sahealthinfo.org/violence/ nimssannual2002.pdf.

9. Richter M. Traditional Medicine and Traditional healers in South Africa, 2003 [homepage on the Internet]. 2003 [cited 2006 Aug 02]. Available from: http://www.tac.org. za/Documents/ResearchPapers/Traditional_Medicine_ briefing.pdf.

10. Health System Trust. Effects of alcohol abuse. HST Update. 1999;43:9.

11. Meel BL, Leenaars AA. Human Immunodeficiency Virus (HIV) and Suicide in region of Eastern Province ("Transkei"), South Africa. Archives of Suicide Research. 2005;9:1-7.

12. Joubert PH. Poisoning admissions of black South Africans. J Toxicol Clin Toxicol. 1990;28(1):85-94.

13. Joubert P. The role of prospective epidemiology in the establishment of a toxicology service for a developing community. SAMJ. 1982;62:853-854.

14. NGOMA. Indigenous healing in Southern Africa: An overview [homepage on the Internet] 2006 [cited 2006 Sep 16]. Available from: http://www.wits.ac.za/izangoma/ part1.asp.

15. Nhachi $\mathrm{CF}$, Kasilo OM. The pattern of poisoning in urban Zimbabwe. J Appl Toxicol. 1992;12(6):435-438.

16. Meel BL. Determinants of Suicide in the Transkei, South Africa. Journal of Clinical Forensic Medicine. 2003;10(2):7176. 